\title{
Characteristics of electricity generation with intermittent sources depending on the time resolution of the input data
}

\author{
F. Wagner ${ }^{1}$ and F. Wertz ${ }^{2}$
}

1 Max-Planck-Institut für Plasmaphysik, Greifswald, Germany

2 University of Chemistry and Technology, Prague, Czech Republic

fritz.wagner@t-online.de

\begin{abstract}
Data on the electricity supply with intermittent renewable sources are made public by the Transmission System Operators and other sources. Data are typically provided in $1 \mathrm{~h}$ increments. In this technical note, we analyse wind and photo voltaic data from the Czech Republic. The analysis concentrates on major characteristics of a supply situation where the annual demand is formally met by scaled-up wind and photovoltaic power. The original data are supplied in $1 \mathrm{~min}$ increments and successively averaged up to $1 \mathrm{~h}$ time resolution. This paper focuses on the dependence of the major supply characteristics on the time resolution.
\end{abstract}

\section{Introduction}

In this technical note, we analyse time series representing basic electricity data of the Czech Republic for the year 2013. The data - load (consumption), wind-, PV-, nuclear and fossil power - have been provided by CEPS [1]. The remarkable aspect of this set is that load and renewable production are on hand with one minute resolution. Data of this kind are made available by many national electricity companies, by ENTSO-E, the European Network of Transmission System Operators [2], and by other sources [3]. However, in most of the cases e.g. in case of ENTSO-E, the data are made public in one hour increments. The four German transmission system operators - 50Hertz Transmission [4], Tennet TSO [5], Amprion [6] and Transnet BW 7 - provide such data with 15 min time resolution.

Wind and photovoltaic (PV) power are presently the only renewable energy forms which can be scaled up to a complete electricity supply by renewable energies (REs). One has to accept, however, that the power accrues in intermittent form. Frequently, data of the electric power flow into the national grids are used to analyse the present situation characterised by a growing share of REs. On this basis several national and EU-wide studies tried to predict the major features of an electricity supply system based exclusively on Res $[8,9,10,11]$.

The objectives of these investigations are to identify - the power which has to be installed to allow a complete supply and the proper mix between wind and PV power,

- the back-up power needed when the RE-systems do not deliver,

- the surplus energies and power levels in periods of excessive wind and solar radiation,

- the capacity of a storage to replace the back-up power,

- the reduction of $\mathrm{CO}_{2}$ production with electricity generation,

- the potential of demand-side-management following the day-night cycle of the REs-power,

- the dynamics of the back-up system when compensating the fluctuating REs share. 
The purpose of this technical note is to investigate the importance of the time resolution of the publically available data in answering some of the above objectives.

\section{Processing of the input data}

The original PV data as provided by CEPS had to be corrected for a gap from September $14^{\text {th }}$ to September $30^{\text {th }}$ where PV data were not registered or not tabulated. The gap was filled using the complementary data from 28.3. to 12.3. of the same year. The total electricity produced by wind power in 2013 according to the CEPS data is lower than those of other sources [12]. As the data which are processed in this report are projected to a $100 \%$ supply by wind and PV, this discrepancy does affect only the power scaling factor which is of no relevance here.

\begin{tabular}{|l|l|c|c|c|}
\hline $\mathbf{2 0 1 3}$ & & $1 \mathrm{~min}$ & $15 \mathrm{~min}$ & $1 \mathrm{~h}$ \\
\hline load & annual consumption (TWh) & 65.1 & 65.1 & 65.1 \\
\hline & maximal power (MW) & 10422 & 10372 & 10337 \\
\hline wind & annual generation (TWh) & 0.48 & 0.48 & 0.48 \\
\hline & maximal power (MW) & 239 & 234 & 223 \\
\hline PV & annual generation (TWh) & 2.0 & 2.0 & 2.0 \\
\hline & maximal power (MW) & 1640 & 1638 & 1625 \\
\hline
\end{tabular}

Table 1 shows the corrected input data for 3 averaging periods.

The produced and consumed energies are independent of the time resolution of the input data; the power levels slightly decrease with increasing averaging.
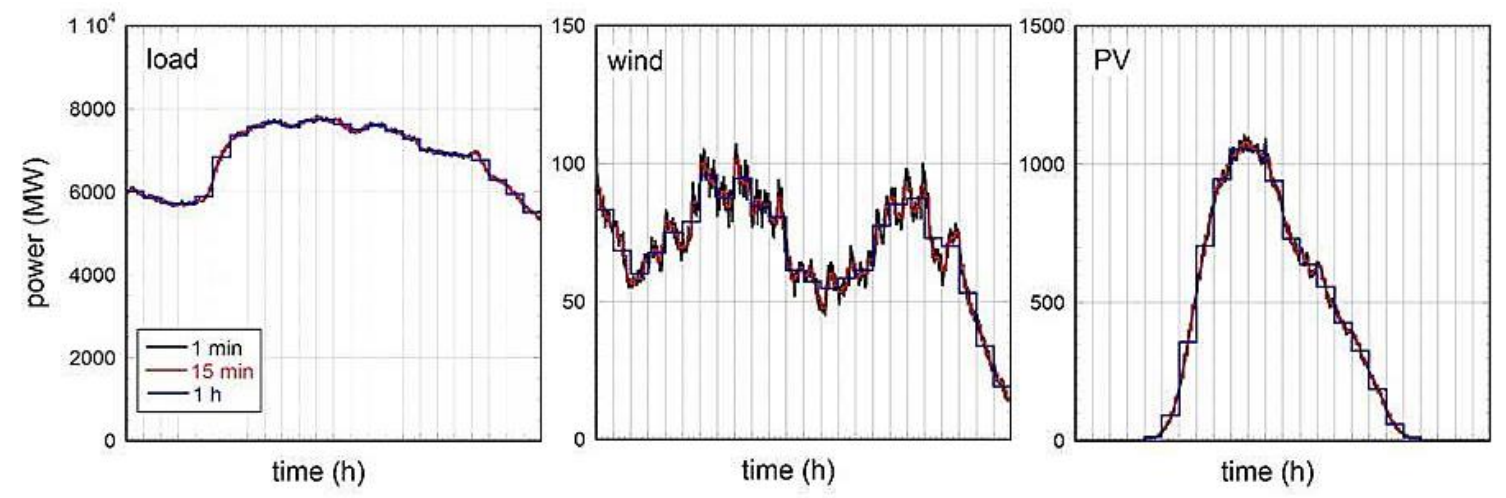

Figure 1. Plotted are the load, wind and PV power for July $25^{\text {th }} 2013$ for three time intervals - the original case with 1 min resolution and after averaging for 15 min or 1 h, respectively.

\section{Comparison of the input data with different time resolutions}

Figure 1 compares load, wind and PV data for 3 data sets: the original data with one minute resolution; data averaged over $15 \mathrm{~min}$; and data averaged over $1 \mathrm{~h}$. The data are shown for one day, for July $25^{\text {th }}$. The comparison documents the impact of averaging and the loss of the shorter-scale dynamics. It is the purpose of this study, to elucidate the consequences of this loss of information in some detail.

\section{Duration curves}


The duration curves of load, wind and PV power are shown in Fig. 2. Plotted are the power values within the database but ordered in falling sequence. To allow for comparison, the three cases are normalised and correspond to $1 \mathrm{TWh}$ consumption in case of the load and $1 \mathrm{TWh}$ production in the cases of wind or PV power, respectively. The duration curves show the usual behaviour - wind and PV distribution do not match the one of the load necessitating a back-up power system to cope with insufficient weather conditions. The high power values are indicative of surplus power which cannot directly be used because it accrues at too high power levels surpassing the load. PV yields specifically high power values because the same amount of energy ( $1 \mathrm{TWh}$ ) has to be produced during half a year. The second half of the year with no PV contribution corresponds to the night hours.

Each of the three curves shown in Fig. 2 consists actually of three curves which lie on top of each other. They correspond to the time resolutions $-1 \mathrm{~min}, 15 \mathrm{~min}$ and $1 \mathrm{~h}$. It is obvious from Fig. 2 that the annual duration curves representing demand and offer do not depend on the time resolution.

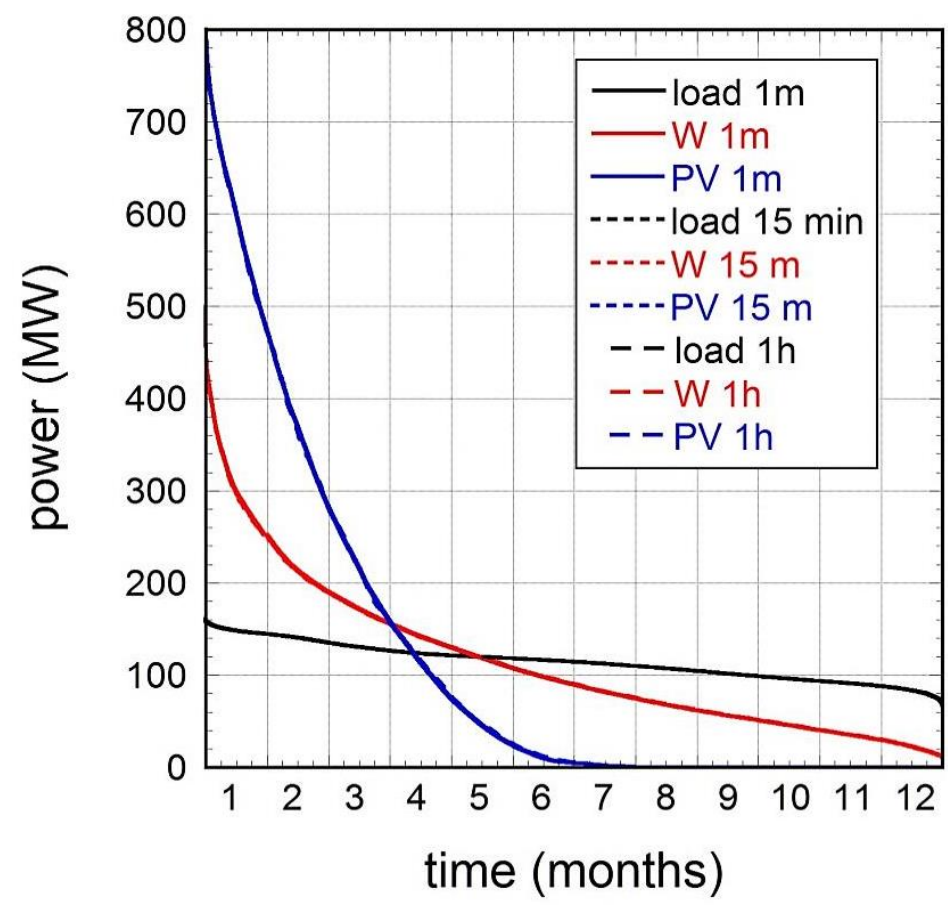

Figure 2. Duration curves for the load (black), wind (red) and PV power (blue) for the three time intervals where the data were recorded.

\section{The optimal mix}

For the extrapolation of wind and PV power to higher values in order to predict the characteristics of a supply system where the REs production covers exactly the annual demand (100\%-case), the ratio of wind to PV power has to be defined. This ratio is, of course, the outcome of political guidelines and market considerations of the investors and cannot be predicted. Therefore, in papers [8-11], a plausible criterion has been used to define the ratio of the two sources: the ratio between the annual electricity production of wind and PV power is such that the necessary back-up energy needed during unfavourable weather conditions is minimal. For the such defined "optimal mix", the conditions are precisely established and the conclusions are simple to take. Any deviations from the optimal mix lead to more back-up energy and power. If this system is based on fossil fuels, it causes more $\mathrm{CO}_{2}$ production as well as other potential negative impacts. 
Figure 3 shows the variation of the annual back-up energy normalised to the annual consumption of 65.1 TWh on the normalised PV energy contribution for the $100 \%$ supply situation. The PV contribution ranges from 0 - in this case the $100 \%$ supply is contributed exclusively by wind power to $100 \%$ - the electricity is generated by PV alone. Again, the three cases considered with different time resolutions of the data fall on top of each other. The minimum of the back-up energy lies at about $20 \%$ of PV energy contribution. The comparison of the three curves basically shows that it does not depend on the time resolution of the underlying data set.

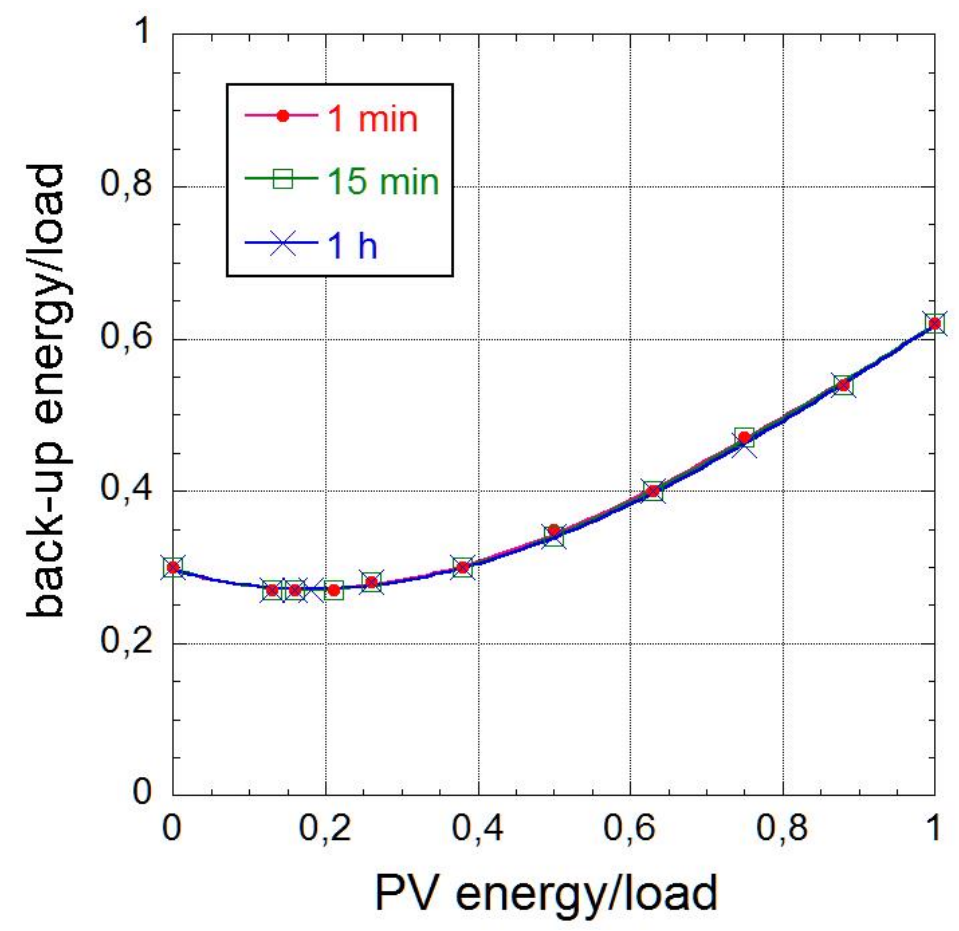

Figure 3. The normalised back-up energy is plotted against the normalised PV energy for the three time intervals where the data were recorded.

\begin{tabular}{|l|c|c|c|c|}
\hline & $1 \mathrm{~min}$ & $15 \mathrm{~min}$ & $1 \mathrm{~h}$ & $\Delta(\%)$ \\
\hline wind power installed (GW) & 27.4 & 26.8 & 25.6 & 7.0 \\
\hline PV power installed (GW) & 8.4 & 8.4 & 8.4 & 0.0 \\
\hline back-up power installed (GW) & 9.2 & 9.1 & 9 & 2.2 \\
\hline surplus power level (GW) & 21.3 & 20 & 19 & 12.1 \\
\hline surplus energy (TWh) & 17.5 & 17.5 & 17.4 & 0.6 \\
\hline required grid capacity (GW) & 29 & 28.5 & 26.9 & 7.8 \\
\hline
\end{tabular}

Table 2: Description of an electricity system supplied completely by wind and PV power (100\% case) under optimal mix conditions. Results are shown for three different averaging times of the input data.

\section{Specification of the $100 \%$, optimal mix case}

Table 2 describes a power system with wind and PV power yielding $100 \%$ of the annual demand under optimal mix conditions. The necessary back-up system is also specified. For the three different 
time resolutions, installed power of wind, PV, back-up, and required grid capacity ${ }^{1}$ are listed, as well as the produced surplus energy. For the $100 \%$ case, the necessary back-up energy agrees with the surplus energy. It is not the purpose of this paper to discuss these results and their consequences. As they do not systematically deviate from the analysis results of other countries, the interested reader may consult ref. [8-11]. Here, we only take note of the outcome of the different time resolutions, which is, however, uncritical. The largest variation is found for the surplus energy level which is underestimated by $12 \%$ when the analysis is based on data with $1 \mathrm{~h}$ resolution.

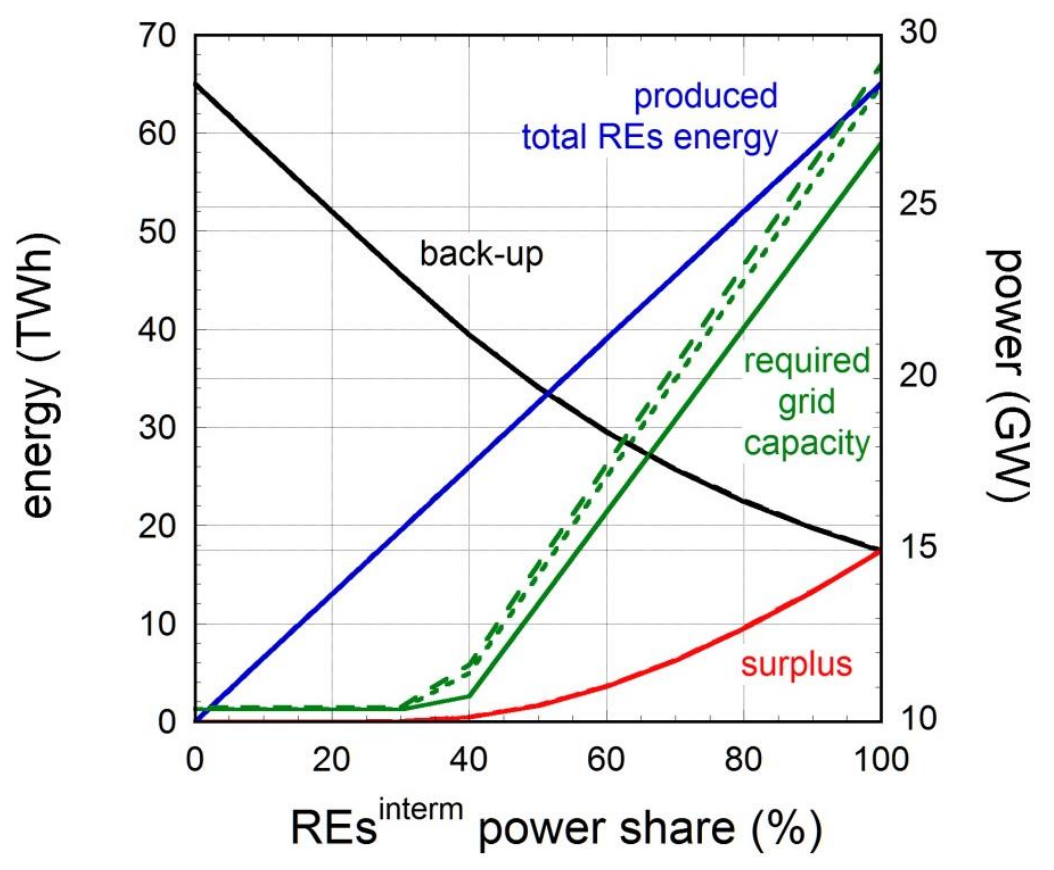

Figure 4. Plotted are the produced total REs, the back-up and the surplus electrical energies versus the power share by intermittent sources. On the right ordinate, the required grid capacity is plotted. The results are shown for the three time intervals where the data were recorded. Time resolution: solid curve: 1 h; dotted curve: 15 min; dashed curve: 1 min.

\section{The $40 \%$ limit}

Previous studies have shown that beyond a $40 \%$ volatile electricity contribution, surplus power and required grid capacity distinctively increase. This trend may indicate that the economic problems with the production of surplus and the technical problems of handling high power loads increase. The $40 \%$ boundary could be considered as a reasonable limitation for the contribution of intermittent sources.

The $40 \%$ limit is recovered also for the CEPS data of the Czech Republic. The results are shown in Fig. 4 for different time resolutions. This limit is also found to be rather independent of the time resolution of the basic power data set.

\section{The power dynamics of the back-up system}

\footnotetext{
${ }^{1}$ The installed powers are identified here with the largest power values in the data base. In reality, the actually installed power levels are higher by typically $20 \%$ because the utility factor uf [8] has to be considered.
} 
The power dynamics is determined by the power gradients which occur within a specified time window. The analyses of the short power gradients in the range of minutes which determine the frequency stability of the grid being controlled by the primary reserve require, of course, the necessary time resolution of the input data [13]. These aspects cannot be explored with the usual time resolution of $15 \mathrm{~min}$ to $1 \mathrm{~h}$ with which power data are generally provided.

Figure 5 shows the power fluctuations $\Delta p=p_{i+1}-p_{i}$ on the one minute level versus the power level $p_{i}$ from which the fluctuation started. $\Delta \mathrm{p}$ is shown for the load (left) and for the back-up system (right) of the $100 \%$, optimal mix case. The lines indicate the power jumps for two technical solutions, a slow one with $3 \%$ per min response of the nominal plant power and for a fast one with $12 \%$ response flexibility. The first value can be associated with a high-efficiency combined cycle power plant (CCPP) and the second one with a lower-efficiency gas turbine (GT) [14].

The variation of the load, shown on the left of Fig. 5 can easily be met if the supply system is comprised by either one of the two considered technologies. As indeed the case, not the full power supply system has to be involved but rather a fraction of it with GT requiring the lower reserve power. In practise, it is a mix of different supply technologies. However, for the back-up system involved in the $100 \%$, optimal mix case shown on the right of Fig. 5 , this is no longer the situation.

Indeed, the grid requires much higher regulation to accommodate intermittent generation than to follow the load. Up to $8 \mathrm{GW}$ of GT are needed to balance the grid (almost the back-up need) with $12 \%$ per min response (nominally $32 \mathrm{GW}$ of CCPP with $3 \%$ per min response). Compared to following the load, the number of power jumps changing sign from one minute to the next one decreases for the back-up system which compensats the fluctuating REs input, an effect which is already noted in the German electricity system today. However, the average amplitude of the jumps, which is the most critical parameter, increases by a factor of four for the $100 \%$, optimal mix case in comparison to the short-time scale dynamics of the load.
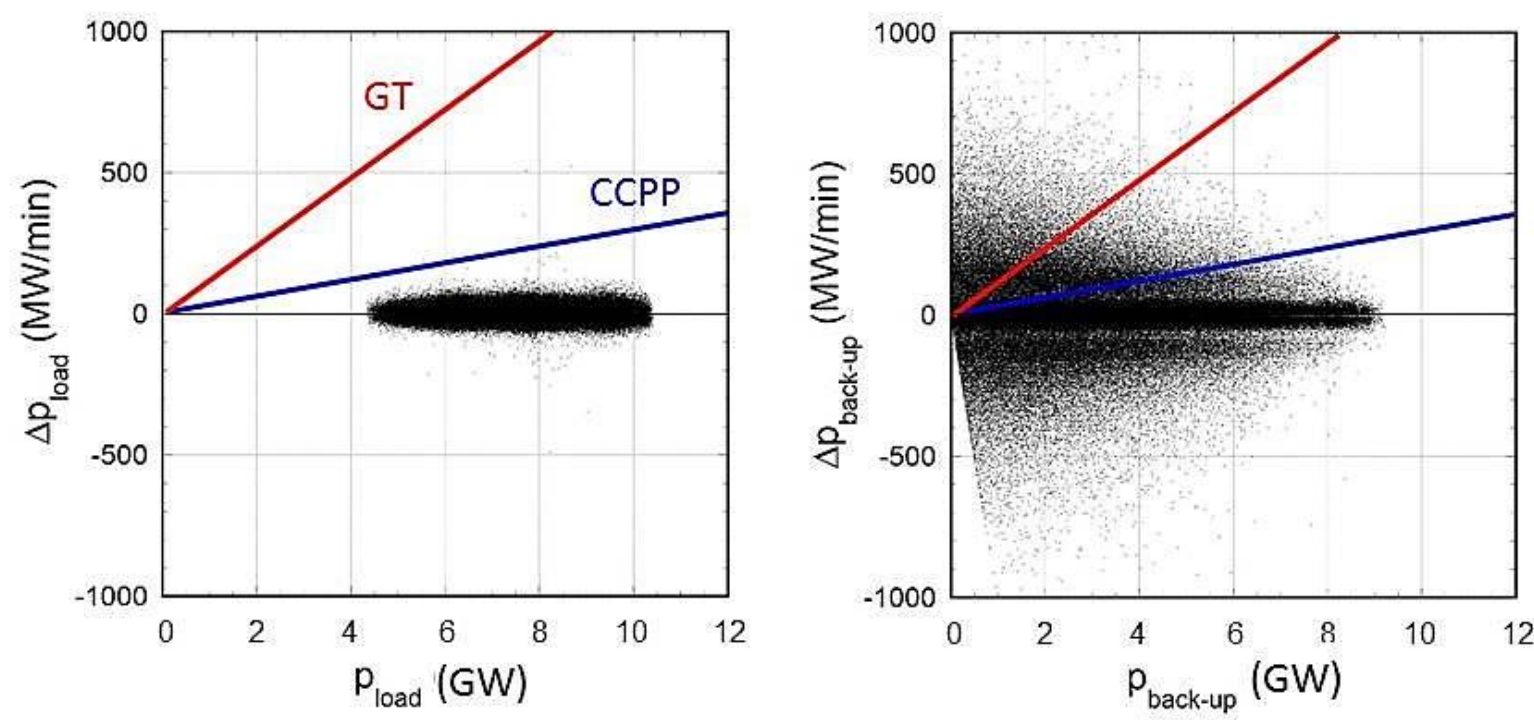

Figure 5. The power increment $\Delta p$ from data point $i$ to $i+1$ is plotted against the power $p_{i}$ for the load (left) and for the back-up system (right) operated under the 100\%, optimal mix condition. The lines represent the response flexibility of systems with 3\% per min of the maximal plant power (blue) and with $12 \%$ (red).(The wedge at the lower left corner is due to the fact that negative values of $\Delta p_{i}$ cannot be lower than $p_{i}$.) 
The longer-period power gradients address the question on how much secondary and tertiary controlling power has to be provided to cope with the dynamic situations of the grid. As the power gradients typically increase with the length of the time window, the selection of a proper time interval is somewhat arbitrary. A time window of $1 \mathrm{~h}$ to reach the nominal power starting from zeropower may be a good choice [13] as it is representative for most types of thermal power stations. This particular aspect in the load following dynamics with intermittent sources is therefore well covered by the primary data even when presented in $1 \mathrm{~h}$ increments.

For completeness, we show the results from the data set of the Czech Republic of 2013 after averaging the data for $1 \mathrm{~h}$. Plotted in Fig. 6 is the power supply capacity, which has to be allocated for controlling the $1 \mathrm{~h}$-power gradients first for the load (black curves) and for the back-up system under $100 \%$, optimal mix conditions (red curves). The results are shown in the form of annual duration curves for three response flexibility rates $-1 \%, 3 \%$, and $12 \%$ per minute. The $100 \%$ optimal mix case will demands typically twice higher grid control capacities than following the current load whereas presently the required control power is fixed by national regulation.

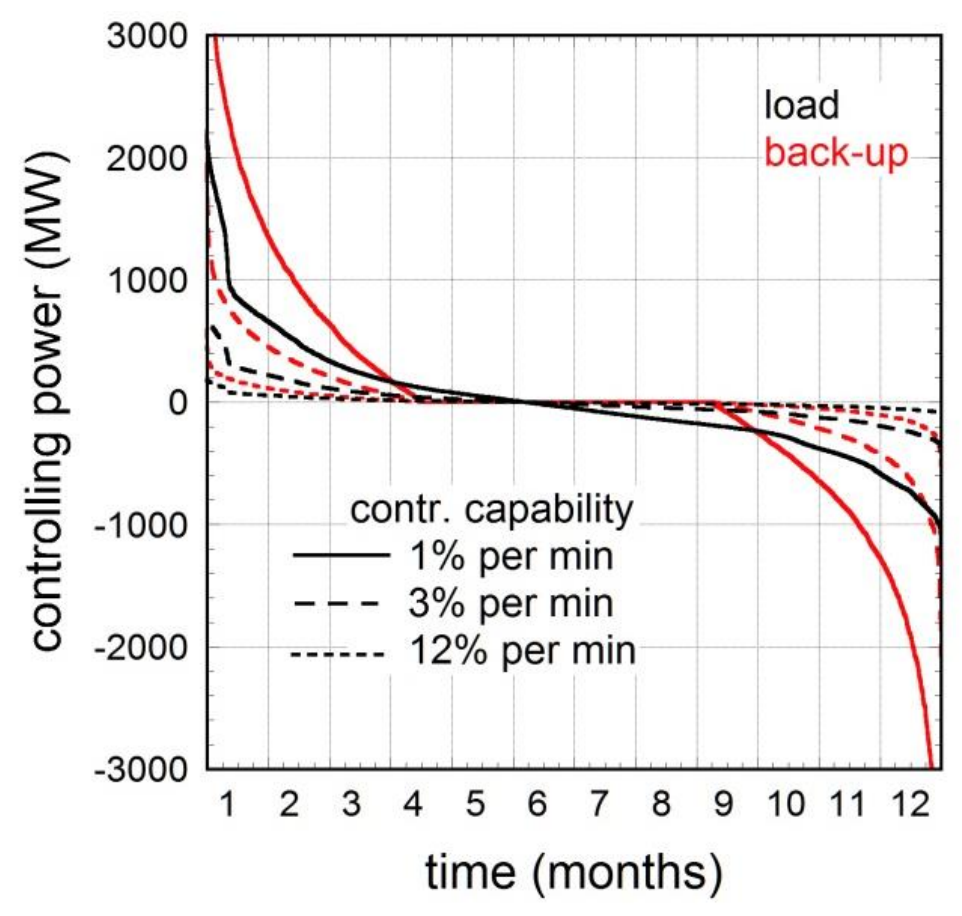

Figure 6. Annual duration curves of the systems which have to be available for regulating the longerterm power gradients (1 h) for the load (black) and for the back-up system (red). The systems considered vary in the response flexibility from $1 \%$ change per minute to $3 \%$ or $12 \%$ change per minute, respectively, for reaching the nominal power from a zero-power start.

\section{Summary}

In summary, we conclude that the analysis of electricity supply systems with intermittent sources based on actual technical data is safely possible even with input data supplied in $1 \mathrm{~h}$ increments for most of the supply and grid characteristics. As far as sizing the grid and back-up system is required, using $1 \mathrm{~h}$ granularity data leads to a little but ignorable underestimation (e.g. compared to the yearby-year variations). Only short-time dynamic aspects of the primary control reserve like the 
frequency control of the grid cannot be addressed correctly. Anyway, primary control reserves are subject to more complex studies and regulated both at national and the European level.

\section{Acknowledgement}

The data used in this study have been supplied by the Czech TSO CEPS which is gratefully acknowledged.

\section{References}

[1] http://www.ceps.cz/ENG/Data/Vsechna-data/Pages/Vyroba.aspx

[2] https://www.entsoe.eu/data/data-portal/Pages/default.aspx

[3] http://www.pfbach.dk/

[4] http://www.50hertz.com/de/Kennzahlen

[5] http://www.tennettso.de/site/Transparenz/veroeffentlichungen/ubersicht

[6] http://www.amprion.net/netzkennzahlen

[7] https://www.transnetbw.de/de/kennzahlen

[8] F. Wagner, Eur. Phys. J. Plus (2014) 129: 20.

[9] F. Wagner, Eur. Phys. J. Plus (2014) 129: 219.

[10] D. GRAND et al., Techniques de l'Ingénieur, IN-301 (2015).

[11] F. Romanelli, Eur. Phys. J. Plus (2016) 131: 53.

[12] CEPS production: $0.323 \mathrm{TWh}$; ERU production: $0.48 \mathrm{GWh}$. http://www.eru.cz/en/elektrina/statistika-a-sledovani-kvality/rocni-zpravy-o-provozu

[13] Consentec: "Description of load-frequency control concept and market for control reserves", http://www.consentec.de/wp-

content/uploads/2014/08/Consentec_50Hertz_Regelleistungsmarkt_en_20140227.pdf

[14] https://en.wikipedia.org/wiki/Combined_cycle 